\section{Duesberg and AIDS}

SIR - In the wake of strong evidence for the causal link between HIV and AIDS, a recent leading article suggested to those who oppose this theory that "there may come a point at which the dissenters forfeit the right to make claims on other people's time and trouble by the poverty of their arguments and the exasperation they have caused"1.

This argument strikes me as rather spurious. If Duesberg has a logical argument that suggests the mainstream view is wrong, it should be heard. If the argument is poor, it will cost little time and trouble, and cause little exasperation. If it is so brilliant as to be irrefutable, it will also cost little time and trouble, and cause little exasperation, being simply accepted. It is only in the grey area in between that scientists will be forced to spend time and trouble and are liable to become exasperated. This grey area, however, is where most scientists spend most of their time. If one does not like spending time and trouble on another's ideas, and becoming exasperated by them, then one is in the wrong job.

Since the publication of Duesberg's seminal paper suggesting that retroviruses are too weak to cause illness ${ }^{2}$, scientists have indeed spent time and trouble in dealing with him. Sadly, in their exasperation, they have used bans, censorship and personal attacks to keep Duesberg silent. He has been ignored, had his funding cut and been denounced in Nature as not belonging to "the grown-up world" 3

Duesberg and his colleagues (the "dissenters') have faced peculiar multilayered review boards when submitting their papers to scientific journals - producing far greater delays and higher rejection rates than normal - while articles that refuted Duesburg's claims have been 'fasttracked', by-passing the normal peer review process. The dissenters have also been excluded from mainstream scientific meetings, forced to meet separately like a clandestine cult. Such unorthodox, and unacceptable, manoeuvres beg the question why.

Duesberg's ideas have received such widespread attention largely because of the failings of the mainstream AIDS establishment. The moral claptrap that has surrounded AIDS since its inception established AIDS as a major killer before one scrap of evidence was obtained. The expectation of AIDS as a widespread virulent killer, a view that most scientists held until very recently, meant that simplistic

\section{Correspondence}

Letters submitted for Correspondence should be typed, double-spaced, on one side of the paper only. ideas as to how HIV worked were liable to be favoured, simplistic ideas that Duesberg was able to attack. So Duesberg could snigger as AIDS failed to penetrate the heterosexual community, smirk as scientists tried to explain the ever-increasing latency of HIV infection to AIDS, and point to his own theory as being closer to the pattern of AIDS development than anything offered by the mainstream.

It was the belief that AIDS was going to explode into the heterosexual community that took up so much time and trouble, not Duesberg. As this misconceived notion fades away, a new science of HIV can emerge, one that will not include Peter Duesberg, but which may nonetheless be troubled by him as a penance for past miscalculation.

\section{Stuart W. G. Derbyshire}

Rheumatic Diseases Centre,

Clinical Sciences Building,

Hope Hospital, Eccles Old Road,

Salford M6 $8 H D$, UK

1. Nature 377, 1 (1995)

2. Duesberg, P. H. Cancer Res. 47, 1199-1220 (1987).

3. Maddox, J. Nature 363, 109 (2993).

\section{III-fated congress}

SIR - The Fifth International Congress of Genetics was held in Berlin in 1927, the Sixth in Ithaca, New York, and the illfated Seventh was originally scheduled for Moscow, not Nazi Germany as a recent News story claimed (Nature 377, 7; 1995).

It was N. I. Vavilov who suggested that it be held in Moscow and he was active in arranging the meeting for 1937 when $\mathrm{H}$. J. Muller arrived and worked with Vavilov to organize the conference. Unfortunately the young T. D. Lysenko was gaining influence, and V. Molotov helped Lysenko in adding Lysenkoists to the planning committee and by making "impossible" demands, such as requesting that there should be no human genetics as that was inherently racist and that there should be no German delegation. The delays and the attacks on genetics by the Lysenkoist camp led to the rescheduling of the congress (for 1939) in Edinburgh. Vavilov hoped as late as 1937 that the congress could be held in Moscow to serve as a bulwark against the growing Lysenkoist movement.

The seventh congress was indeed illfated. The war broke out as the congress ended and a ship (the Athenia) in which some delegates were returning to the United States was torpedoed and a few geneticists lost their lives (most were saved).

\section{Elof Axel Carlson}

Department of Biochemistry

and Cell Biology,

State University of New York,

Stony Brook, New York 11794-3351, USA

\section{Born in summer?}

SIR - Among the students who entered Porto faculty of medicine in the past three years, Azevedo et al. observed a significantly higher ratio of students born during the second trimester of the year and discussed possible effects of birth dates on early development of the brain (Nature 376, 381; 1995). Although their result is interesting, the number of the students

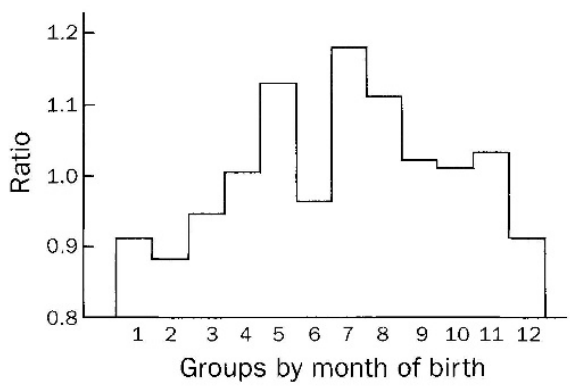

examined (263) seems too small to establish the observation.

I investigated the birth dates of 2,525 graduates from the faculty of medicine at the University of Tokyo during the past 25 years and grouped them by month. These graduates were also among the most successful high-school students in terms of achievement in written examinations. In each group, the numbers of graduates observed were divided by those expected from births by month in Japan during 1947-71 when the graduates were born. The average ratios are shown in the figure. There is a significant difference in the ratios between groups born during the summer and winter, with the highest in July and the lowest in February $(P<0.01)$. Of the four trimesters of the year, it is not the second but the third trimester that shows the highest ratios, which cannot be explained by a relative age advantage because April is the start of the academic year in Japan.

My result does not completely agree with the observation of Azevedo et al.; nevertheless, it is also suggestive of the possible effects of birth dates on academic success. According to my result, birth during summer seems advantageous. Why summer? Although the reason is unclear, one possible explanation is that babies born in summer spend their first couple of months under the least restraint of heavy clothes and of illness and with the opportunity of staying outdoors, which would increase their physical movement and openness to external stimuli, both probably important for early development of the brain. This may also explain the disproportionately low ratio in the group of June, which is Japan's rainy season.

\section{Takanari Gotoda}

Molecular Medicine Group,

Hammersmith Hospital,

DuCane Road,

London W12 ONN, UK 